\title{
Regionalization of Baseline Climatologies and Time Series for the Okavango Catchment
}

\author{
Thomas Weinzierl, Olaf Conrad, Jürgen Böhner \& Jan Wehberg
}

\begin{abstract}
The resolution of modern Global and Regional Climate Models is sufficient for many purposes. Nevertheless, the downscaling of model output is necessary when a higher spatial resolution is needed for smaller scale applications. This article introduces intermediate results of an approach for climate regionalization using the free and open source GIS software SAGA, applied on historical and future REMO regional climate model scenarios for the Okavango River Basin of southwestern Africa. The approach makes use of an SRTM digital elevation model and regionalizes temperature via a linear elevation correction/polynomial fit and precipitation with a geographically weighted regression. The results are then compared to the WorldClim interpolated station dataset. For four locations of interest without historical climate observations, time series are generated
\end{abstract}

Keywords: downscaling; elevation correction; geographically weighted regression; regional climate.

Regionalização da linha de base climatológica e séries temporais para a Bacia do Okavango

Resumo: A resolução dos Modelos Climáticos Globais e Regionais modernos é suficiente para muitas finalidades. No entanto, a redução de escala do modelo generado é necessária quando uma resolução espacial mais alta é necessária para aplicações em menor escala. Este artigo apresenta os resultados intermediários de uma abordagem para a regionalização climática usando a fonte GIS gratuita e aberta, o software SAGA, aplicado em cenários históricos e futuros do modelo climático regional REMO para a bacia do rio Okavango no sudoeste da África. A abordagem utiliza um modelo digital de elevação SRTM e regionaliza a temperatura através da correção de elevação linear/polinômio e da precipitação com uma regressão geograficamente ponderada. Os resultados são então comparados com o conjunto de dados da estação interpolada WorldClim. Para quatro locais de interesse sem observações climáticas históricas são geradas séries temporais.

Palavras-chave: correção de elevação; modelo de clima regional; redução de escala; regressão geograficamente ponderada.

Received: 29 August 2013 - Accepted: 19 December 2013

\section{Introduction}

The Okavango River is called the 'lifeline' of southwestern Africa (Mendelsohn \& Obeid 2004) as it provides water in an otherwise largely arid environment and a considerable number of people in the three riparian states directly or indirectly derive their livelihoods from it. Originating in the humid Bié Plateau of central Angola, the river crosses Namibia's Caprivi Strip and disperses into the largest inland delta in the world, a complex series of heavily vegetated channels and shallow basins in Botswana. The climate in the Okavango Catchment is strongly influenced by the Subtropical High Pressure Zone bringing in dry air from the south and the Intertropical Convergence Zone bringing in moist air from the north (Mendelsohn et al. 2002). Rainfall in the region is highly seasonal with a wet season in the (south) summer, typically from around October to March and a dry season from about April to September. Temperatures are generally high with an extreme daily variability and high evaporation rates. Namibia is one of the driest countries in the world and has no perennial rivers at all originating within its borders. It benefits from the summer rainfalls mostly in its northeastern parts while the southwest has average precipitation rates of only $50 \mathrm{~mm}$ and less. The reason for this gradient is the cold Benguela Current in the South Atlantic with its upwellings at Namibia's coasts. Southern Africa in general and the Okavango basin in particular are subject to processes such as landuse, socioeconomic and climatic changes (Mbaiwa 2003 \& 2011, Weinzierl \& Schilling 2013) and a hotspot for biodiversity loss (Biggs et al. 2008). These changes require appropriate adaptation measures as they directly and indirectly affect many sectors like environment, agriculture, water resources, energy, wildlife and diseases. Therefore, policy makers are in need of suitable spatial and nonspatial information such as maps and time series that allows them to identify vulnerable areas, estimate the range and magnitude of climate change impact and thus make reasonable decisions. Assessments of future climate development in the catchment are in high demand because water is a key ecosystem service and the local economies depend on its availability.

The study region can be characterized as a poor data region, as climate observations for southwestern Africa, especially Angola, are relatively scarce and often low quality with only very short measured periods. This is mostly due to historic reasons such as the decades of civil war in parts of the catchment. In their 4th assessment report, the Intergovernmental Panel on Climate Change IPCC indicates a temperature increase above the global annual mean warming for southern Africa toward the end of the century, accompanied with a very likely decrease in precipitation. Especially the dry subtropical regions are expected to be a hotspot of global 


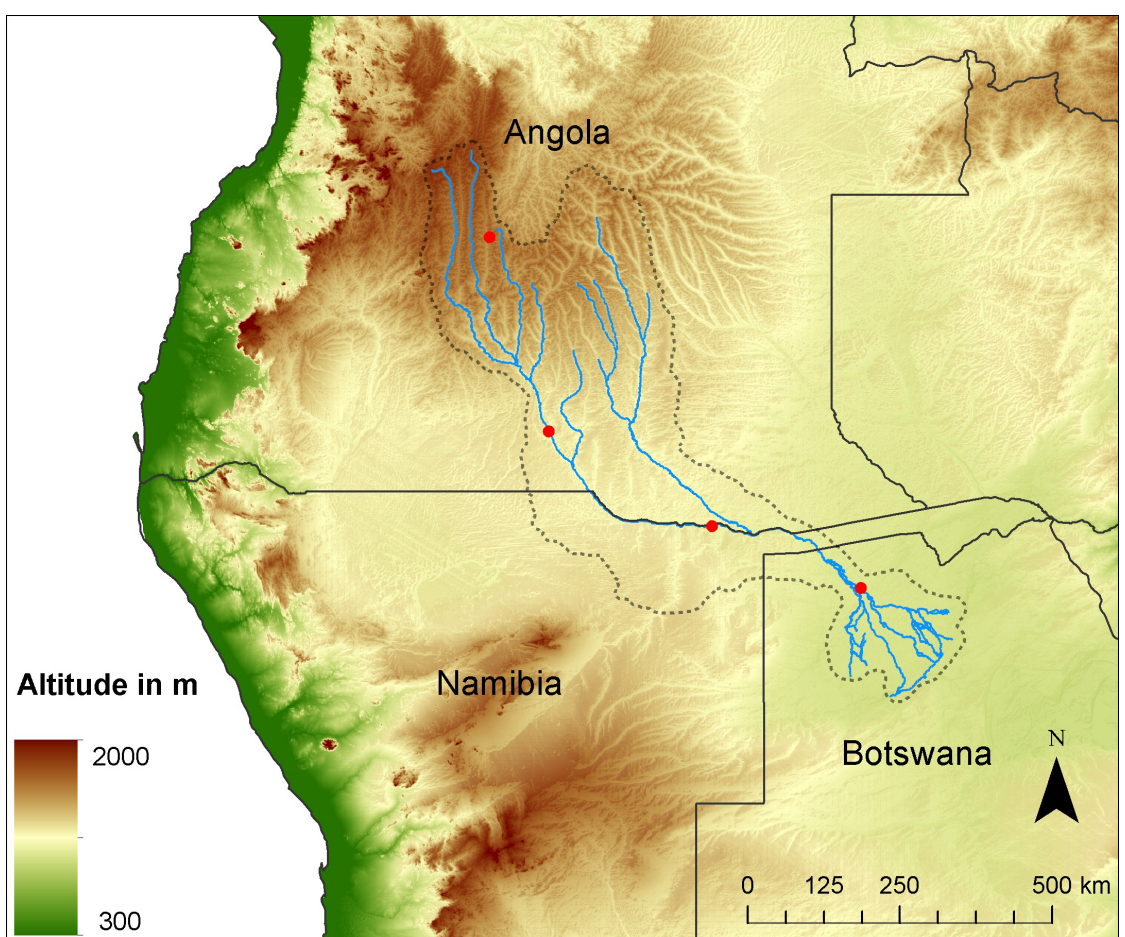

Fig. 1: SRTM Digital Elevation Model of the TFO model domain resampled to the target resolution of $1 \mathrm{~km}$. The Okavango River is marked blue, the active catchment black and the four core sites red.

warming (IPCC 2007). In the recent years, Global Climate Models (GCM) have emerged as an adequate tool to predict large-scale climatic conditions and assess the impacts of anthropogenic loading of the atmosphere with greenhouse gases (von Storch et al. 1993). These models undergo constant improvement and today reach horizontal resolutions between 100 and $300 \mathrm{~km}$. However, many critical impacts of climate change will occur at sub-regional or local scales, for example at drainage basins and agricultural areas (Wetterhall et al. 2005) but it will not be possible to accurately compute scales of $50 \mathrm{~km}$ or less with a Global Climate Model in the near future (Spekat et al., 2008). Therefore, the regionalization of GCM output is required for analyses on smaller scales. A common practice is to use nested dynamical models (RCM -
Regional Climate Models) such as REMO that simulate climatic variables of a certain region through the laws of physics and achieve resolutions of $25 \mathrm{~km}$ and higher. For even finer resolutions, further downscaling is required. While there are multiple ways of resolving subsynoptic features using physical or statistical relationships with corresponding upsides and downsides (concerning e.g. technical complexity, computing time and physical consistency), the possibilities for the application of small scale climate data are also "endless", ranging from impact studies to water supply, economy, tourism and the identification of bioclimatic envelopes. The purpose of this article is to present preliminary results of the authors' regionalization scheme for RCM output for the Okavango region. The work was conducted within the interdisciplinary project "The Future Okavango" (TFO), aiming at the improvement of land use and resource management in the Okavango Catchment as part of the BMBF (German Federal Ministry of Education and Research) funding measure "Sustainable Land Management".

\section{Data}

Four local study sites have been chosen by the project participants: Chitembo (Angola), Caiundo (Angola), Mashare (Namibia) and Seronga (Botswana). At these locations, measurement of climate variables has only very recently begun and there is a need for historical and future model data (time series) while spatially explicit data is of interest at the catchment level, for example to determine hotspots of climate change within the domain. Unless otherwise stated, the authors worked with monthly data, though the presented approach is transferable to any other temporal resolution without difficulty assuming the necessary data is available.

The climate data to be regionalized had been computed in a horizontal resolution of $25 \times 25 \mathrm{~km}$ with the Regional Climate Model REMO (Jacob 2001) forced with the Global Circulation Model ECHAM for the domain of longitude $8^{\circ}$ to $32^{\circ}$, latitude $10^{\circ}$ to $27^{\circ}$. Haensler (2011) showed that REMO well reproduces the main temporal and spatial climatic features of the southern African region including the strong seasonality and large interannual variability of rainfall patterns and therefore concludes that the model is suitable for climate studies in the region despite some coastal warm bias. Included is a historical control run spanning the period 1950 - 2005 and two future emission scenarios from $2006-2100$ in daily temporal resolution. The dataset comprises 18 climate variables at surface level as well as seven tropospheric variables at the $500,700,850,925$, and

Table 1: Overview of the TFO core sites

\begin{tabular}{ccccc}
\hline TFO Core Site & Country & Coordinates & Altitude in m (REMO) & Altitude in m (SRTM) \\
\hline Chitembo & Anola & $16.925 \mathrm{E},-13.630 \mathrm{~S}$ & 1542 & 1560 \\
Caiundo & Angola & $17.805 \mathrm{E},-16.495 \mathrm{~S}$ & 1181 & 1155 \\
Mashare & Namibia & $20.213 \mathrm{E},-17.898 \mathrm{~S}$ & 1076 & 1068 \\
Seronga & Botswana & $22.415 \mathrm{E},-18.816 \mathrm{~S}$ & 985 & 982 \\
\hline
\end{tabular}


$1000 \mathrm{hPa}$ level. For this approach, the most important variables are temperature, precipitation and the speed and direction ( $\mathrm{u}$ - and v-components) of the wind. In the TFO context, two IPCC scenarios or RCP (Representative Concentration Pathways) are used, RCP4.5 as a medium-low and RCP8.5 as a high scenario, in which the values 4.5 and 8.5 indicate the projected increase in radiative forcing $\left(\mathrm{W} / \mathrm{m}^{2}\right)$ until the year 2100 (Meinshausen et al. 2011).

The Digital Elevation Model (Fig. 1) used for the elevation correction and as a predictor of the Geographically Weighted Regression of model output was originally derived by the first Shuttle Radar Topography Mission (SRTM) in the year 2000 and upgraded 2005. It was published by the US Geological Survey (USGS) and is freely available in resolutions of up to $90 \mathrm{~m}$ worldwide. For further use, the DEM was projected to geographic coordinates and resampled to fit the target resolution of $1000 \mathrm{~m}$. It is quite common for this kind of DEM to contain error sinks and nodata-gaps known as voids even in the newest versions. These voids were closed using spline interpolation as recommended for small and medium-sized gaps in higher altitudes and heterogeneous terrain by Reuter et al. (2007) in their evaluation of different interpolation methods for SRTM voids.

As mentioned above, climate observations for the Okavango Catchment, especially the Angolan part, are scarce and often heavily fragmented. For comparison with model data, two sources of observational data are used. First, the renowned Global Historical Climate Network (GHCN) monthly dataset (Lawrimore et al. 2011), which contains point-source data for a number of stations in the domain but not necessarily inside the catchment. Whenever possible, the climate stations nearest to the catchment were used. Second, the gridded Worldclim dataset (Hijmans et al. 2005) of temperatures and precipitation, compiled and interpolated from average monthly station data to a resolution of 30 arc-seconds or $1 \mathrm{~km}^{2}$.

\section{Methods}

This publication is focused on the regionalization of temperature and precipitation with a polynomial fit of 3D temperature data and a geographically weighted regression of $2 \mathrm{D}$ precipitation data respectively. As a comparison, temperature is also regionalized by correcting the altitude with a constant lapse rate.

The handling of large data quantities such as climate data makes certain demands concerning the choice of tools used in the process. There is no perfect approach and tools may differ from researcher to researcher and from institution to institution, however, certain useful instruments emerged over time. An advantage of the presented approach is that, besides an up-to-date Personal Computer (using any of the established operating systems) and the discussed software and data, nothing else is needed. For easy reproduction, an effort was made to utilize freely available opensource software rather than commercial products.

The storage of climate data in netCDF file format has become widely established in climate sciences over the recent years. A metadata standard for netCDF files has been introduced with the so-called "climate and forecast (CF) metadata conventions". Based on this standard a number of applications have been developed that allow relatively easy handling of such data. One of them is CDO (Climate Data Operators), a command-line-based set of tools for the basic handling of netCDF files,

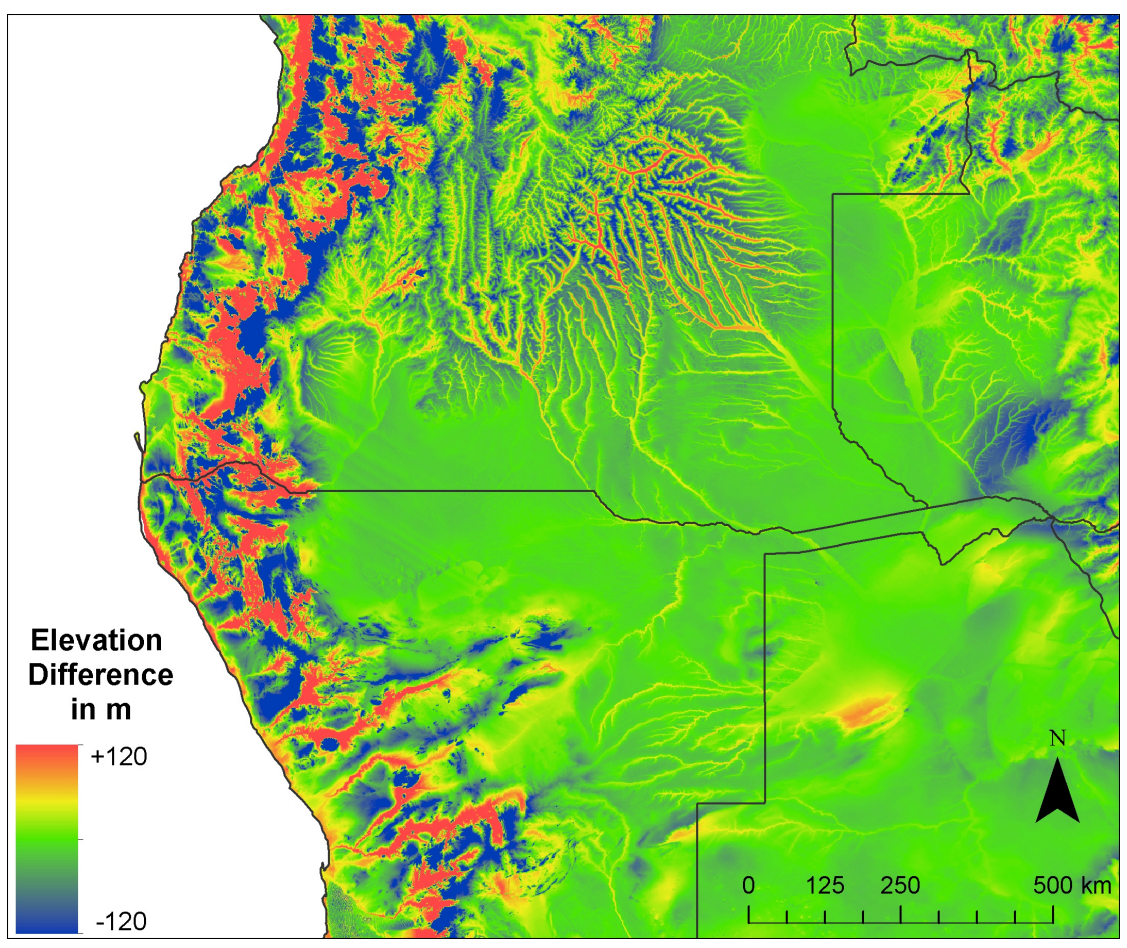

Fig. 2: Difference between 25x25km REMO elevation and $1 \times 1 \mathrm{~km}$ SRTM. Red areas are underestimated and blue areas overestimated by the regional climate model. In green areas (predominantly flat areas) the assumed elevation approximately coincides. developed by the Max Planck Institute for Meteorology in Hamburg for processing and analysis of data produced by a variety of climate and numerical weather prediction models. Supported basic tasks include file operations, simple statistics, arithmetics, interpolation or the calculation of climate indices (Kaspar et al. 2010). Visualization of spatial explicit data, geographical projection, resampling, calculations and further tasks are carried out in SAGA (System for Automated Geoscientific Analyses), a cross-platform open source Geographic Information System (GIS) software developed by the Departments of Physical Geography in Göttingen and Hamburg (Conrad 2006). Its modular structure enables the exchange and addition of libraries for a wide range of geoscientific analyses. As geoprocessing tasks are often performed on a number of different datasets or on large datasets with numerous records, they can be time consuming. The SAGA distribution therefore contains a command-line version (SAGA CMD) for the automation of simple to relatively complex work flows by scripting in Python or other languages. The scripts are recyclable and can be used again when written data nonspecific (Tucker 2004). 


\section{Temperature}

Temperature controls a large variety of environmental processes and is an essential input parameter for land surface models, for example in hydrology, ecology and climatology (Gao et al. 2012). Throughout the troposphere (up to about $8 \mathrm{~km}$ above the poles and about $18 \mathrm{~km}$ over the equator), with an increase in elevation and therefore an increasing distance from the heating earth surface, air temperature decreases (Mohanakumar 2008). The vertical lapse rate averages $6.5 \mathrm{C}$ per kilometer or $0.0065 \mathrm{C}$ per meter (Root 2011). GCM/RCM temperature data can be regionalized by performing an elevation correction, based on the assumption that elevation is the main factor determining the distribution of surface temperature (Feulner et al. 2013). Because of the "coarse" resolution $(25 \mathrm{x}$ $25 \mathrm{~km}$ ) of the RCM data, the altitude assumed by the model is relatively inaccurate (Fig. 2), which (especially in mountainous areas) has a distorting effect on variables that change with elevation. Therefore, an elevation correction is required, for which there are two established methods, the linear and polynomial. In a first step, DEM and model data are projected to the same coordinate system and resampled to fit the target resolution of $1 \mathrm{~km}$ using spline interpolation (Conrad 2006). The resampling process for itself adds no information to the data. While the linear correction method uses a constant vertical lapse rate to correct $2 \mathrm{~m}$ temperature, a polynomial trend can be calculated and fitted through the free atmosphere temperatures (FAT) at certain pressure levels, provided that three-dimensional data is available. When added a high resolution DEM, a value for the corrected surface height can be derived from the polynomial equation. As shown by Kawohl (2013), the differences between corrected elevation with linear and polynomial method are marginal, except for very mountainous regions. The southern part of the Okavango Catchment is relatively plain, so the temperature values of the RCM are already quite exact in this area because the smoother the topography, the more realistic the elevation assumed by REMO (Fig. 2).

\section{Precipitation}

Precipitation is a crucial factor in this mainly semiarid region and the most important driving variable in hydrological modeling and analysis (Wetterhall et al. 2005). Precipitation downscaling is performed using Geographically Weighted Regression (GWR) as proposed by Brunsdon et al (1998). Instead of fitting one global regression model GWR creates a set of local regression models, for which the influence of each observation is weighted according to its distance to the

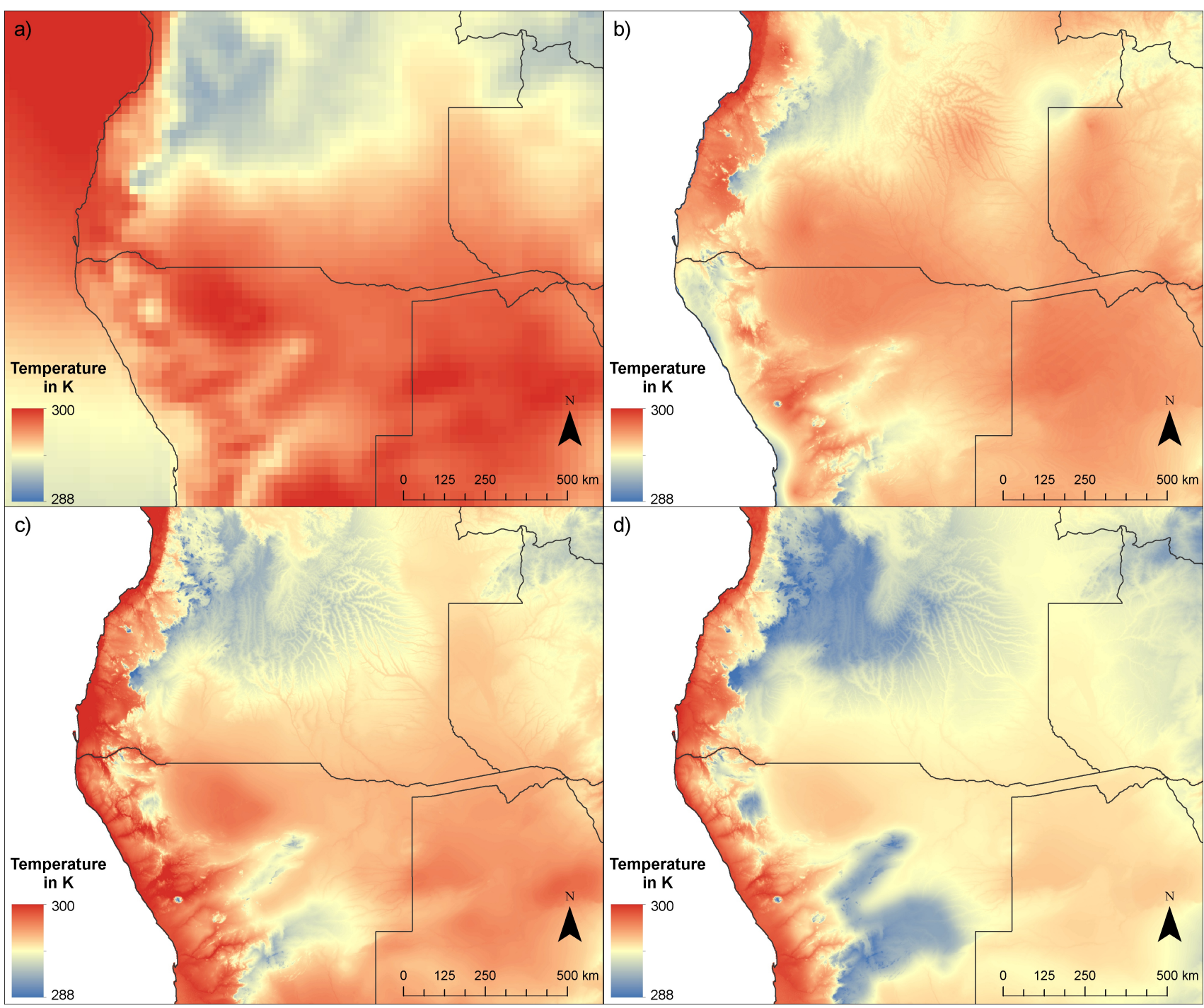

Fig. 3: Average temperature $1950-2000$ for March in a) original REMO 25x25km resolution b) Worldclim $1 \times 1 \mathrm{~km}$ interpolated station data c) $1 \times 1 \mathrm{~km}$ altitude adjusted T2m and d) $1 \times 1 \mathrm{~km}$ interpolated Free Atmospheric Temperatures. 


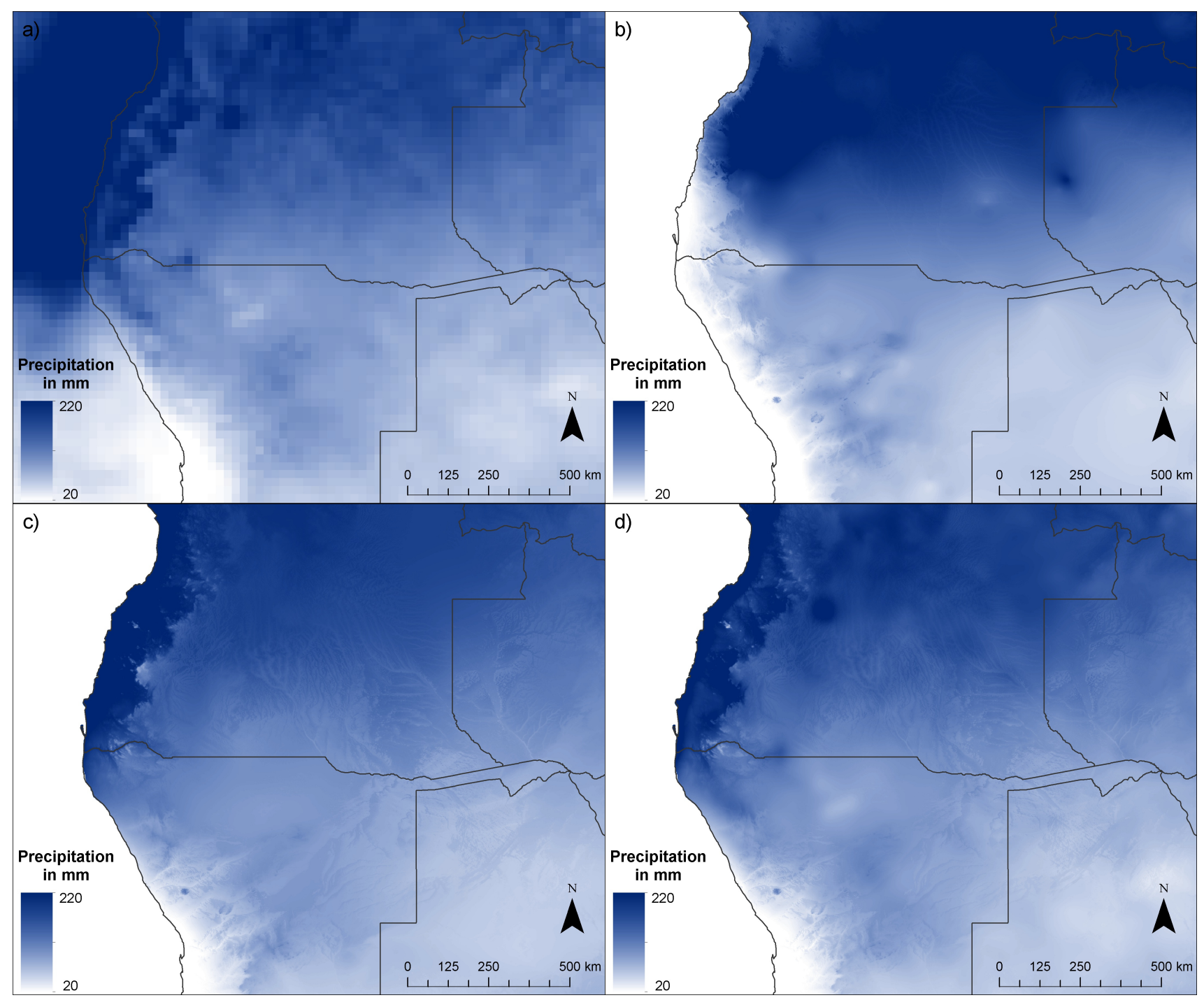

Fig. 4: Average precipitation 1950-2000 for March in a) original REMO 25x25km, b) Worldclim interpolated station data 1x1 km, c) downscaled with GWR and d) GWR including residual correction.

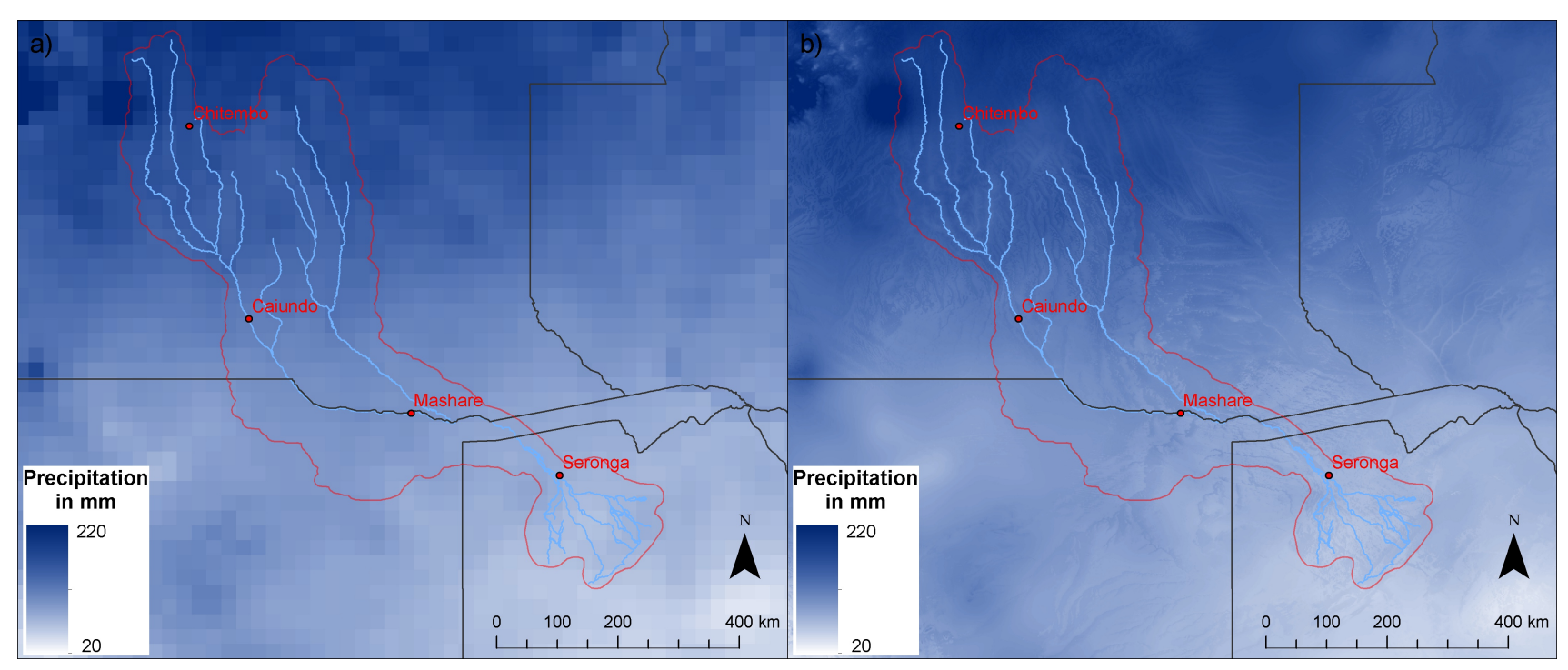

Fig. 5: Average precipitation 1950-2005 for March in a) original 25×25km and b) downscaled $1 \mathrm{~km}$ resolution. The active Okavango Catchment and four TFO core sites are marked in red. 
model location. This way GWR is able to reflect in dependence of the location changing relations between observed and predictor variables Brunsdon et al. (2001) showed the advantages of GWR compared to global regression for the regionalization of precipitation using elevation as single predictor. In this study the modeled precipitation is taken as observation. Besides elevation a windward-leeward index has been used as additional predictor, assuming that areas exposed to wind force the moving air masses to rise and thus yield a higher precipitation than areas in the lee side. This index is calculated for each month separately based on the DEM and the modeled wind field.

To generate time series for the four TFO core sites and to be able to compare the model output with climate station observations, nearest-neighbor interpolated values for the 9 grid cells around each location of interest were extracted from the regionalized data. This technique was used to compensate potential deviances. For a better overview and to exclude the extreme intra-year variations, the data was combined to a yearly temporal resolution. An 11-year symmetric moving mean was calculated and added to better illustrate long-term trends.

\section{Results and Discussion}

The regionalized monthly temperature and precipitation values were compared with available station observations from the GHCN network. In doing so, the heightcorrected temperatures were found to represent the observed data quite good with comparatively low Root Mean Square Errors (Fig. 6b). In the (south) winter months, the model overestimated the temperatures a little at most stations (figure 6a). As the winter months are also the dry season in the region, both mean deviation and RMSE at the precipitation stations are very low for that time period because there is practically no precipitation. In the summer months, the model tends to overestimate rainfall by around $20-60 \mathrm{~mm}$ each month (Fig. $6 \mathrm{c} \&$ d).

A comparison of the regionalized monthly long-term values from 1950 to 2000 with the gridded WorldClim dataset interpolated from stations, also in $1 \mathrm{~km}$ resolution, shows that the model reproduces the regional climate in terms of temperature and precipitation very well
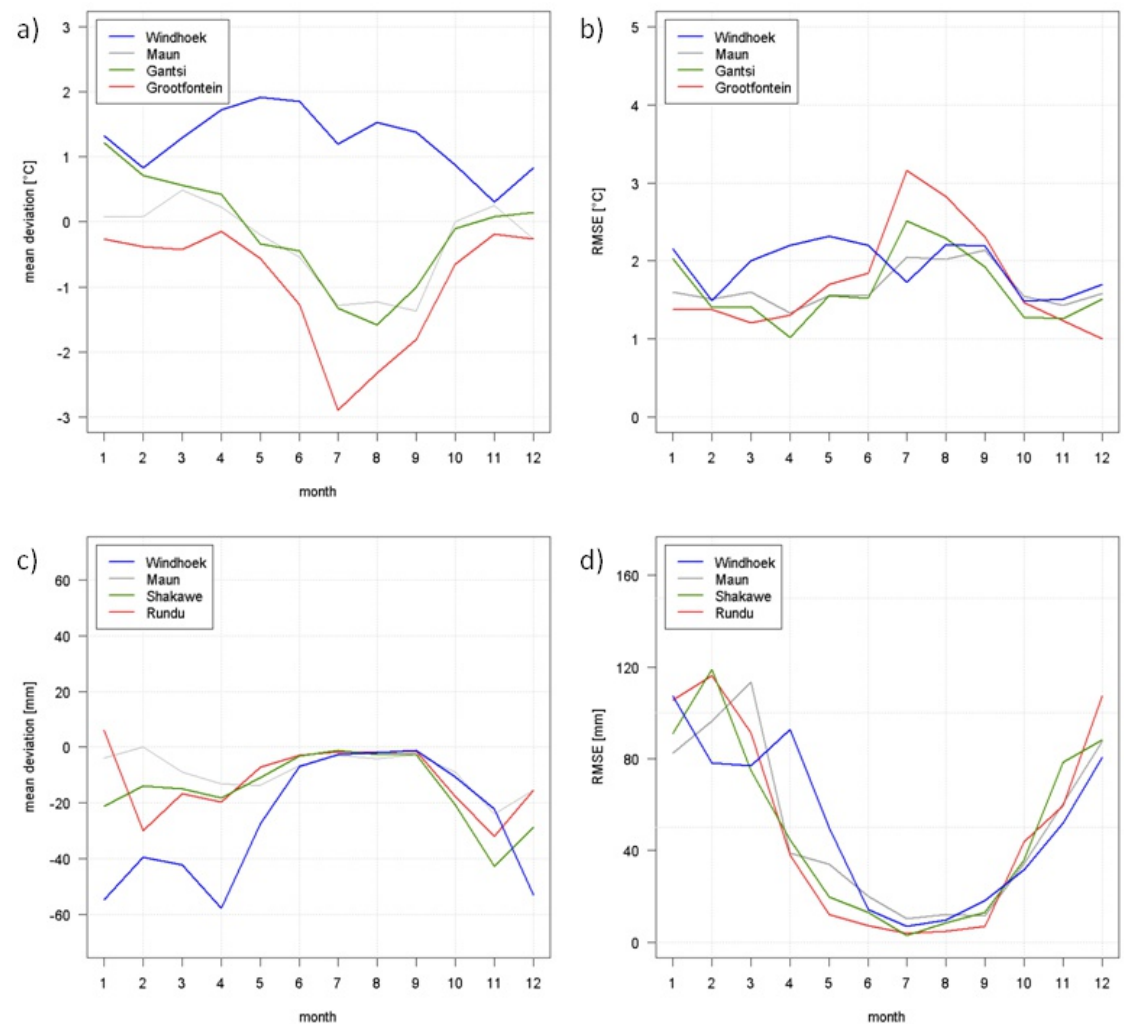

Fig. 6: a) mean deviation and b) root mean square error of regionalized and observed temperature as well as c) mean deviation and d) root mean square error of precipitation at different GHCN stations in the domain.

(Fig. 3 and 4), except the warm and wet bias mentioned in chapter 2 , especially in the northwestern coastal regions. Precipitation is best represented by the GWR including residual correction. Time series generated from the regionalized data (see Fig. 7 to 14) suggest that all four core sites will experience rising temperatures in the future. The estimated change ranges from 2 to $2.5^{\circ} \mathrm{C}$ in scenario rcp4.5 to almost $6{ }^{\circ} \mathrm{C}$ in scenario rcp8.5. Most of the core sites with the exception of Chitembo as the northernmost site also show a decreasing precipitation of around $20 \%$ in the scenarios, most distinctive in the second half of the century. This development might put further pressure on the already stressed water situation of the present.

The added value of the performed elevation correction increases with the topography of the targeted area. In this case study, the linear $\mathrm{T} 2 \mathrm{~m}$ correction performs better than the polynomial interpolation of FAT. A likely reason is that in the available dataset, only two to three of the available pressure levels are situated above the surface for most of the domain.

Note that the results presented have not yet been bias-corrected. For a biascorrection, an in-depth residual analysis of temporal and spatial regularities as well as observed data with substantial spatial and temporal resolution for the region is required. However, working with monthly data, an adjustment according to Skaugen et al. (2002) using the mean monthly ratio between model and observed precipitation in the control period and a monthly regression equation of temperature might lead to satisfactory results.

\section{Conclusions}

The article presented preliminary results of the climate regionalization scheme with a target resolution of $1 \mathrm{~km}$ for the Okavango region. With the presented methods, a dataset of high resolution monthly mean surface temperatures and precipitation was generated for the historical timeframe of 1950-2005 and two scenarios from 2006-2100. An elevation correction of temperature data added value especially in the more mountainous areas of the northern catchment. For the downscaling of precipitation data, a Geographically Weighted Regression algorithm with DEM based orographic parameters as predictors so far proved to be a reasonable approach. A possibility to enhance this 
method is to find additional suitable predictors such as remote sensing data and its derivatives (e.g. NDVI, NPP). The presented methods are implemented in the open source software SAGA-GIS and therefore freely available to the scientific community for reproduction and improvement. The downscaled results can, for example, be used to improve spatially explicit assessments of the projected temperature and precipitation changes, by comparing the scenarios with a historic reference period. Also, a comparison between the presented results and those using different GCM/RCM combinations (with EC-EARTH, WRF) as well as a deduction of parameters such as evaporation is currently in progress. Naturally, regionalized climate data can only be as good as the model data that is used for input. With the rapid technical development in recent years, the underlying global and regional climate models undergo constant improvement.

\section{Acknowledgement}

We would like to thank our colleagues in the TFO project for their support and many stimulating discussions. Also, we owe special thanks to our project partners from the Climate Service Center Hamburg, who run the REMO simulations this work is based on.

\section{References}

Biggs, R., Simons, H., Bakkenes, M., Scholes, R.J. , Eickhout, B., van Vuuren, D., Alkemade, R. (2008): Scenarios of biodiversity loss in southern Africa in the 21 st century. - Global Environmental Change 18: 296-309. CrossRef

Brunsdon, C., Fotheringham, S., Charlton M. (1998): Geographically Weighted Regression - Modelling Spatial NonStationarity. - Journal of the Royal Statistical Society. Series D (The Statistician) 47: 431-443. CrossRef

Brunsdon, C., McClatchey, J., Unwin, D.J. (2001 ): Spatial Variations in the Average Rainfall-Altitude Relationship in Great Britain: An Approach Using Geographically Weighted Regression. International Journal of Climatology 21: 455-466. CrossRef

Conrad, O. (2006): SAGA - Entwurf, Funktionsumfang und Anwendung eines Systems für Automatisierte Geowissenschaftliche Analysen. Ph.D. thesis, University of Göttingen.

Feulner, G., Rahmstorf, S., Levermann, A., Volkwardt, S. (2013): On the origin of the surface air temperature difference between the hemispheres in earth's present-day climate. - Journal of Climate 26: 7136-7150. CrossRef

Gao, L., Bernhardt, M., Schulz, K. (2012): Elevation correction of ERA-Interim temperature data in complex terrain. Hydrology and Earth System Sciences 16: 4661-4673. CrossRef

Hänsler, A. (2011): Impact of climate change on the coastal climate of SouthWestern Africa. Dissertation, University of Hamburg.

Hijmans, R. J., Cameron, S. E., Parra, J.L., Jones, P.G., Jarvis, A. (2005): Very high resolution interpolated climate surfaces for global land areas. - International Journal of Climatology 25: 1965-1978. CrossRef

IPCC (2007): Parry, M.L., Canziani, O.F., Palutikof, J.P., van der Linden, P.J. Hanson, C.E. [Eds]. Climate Change 2007: Impacts, Adaptation and Vulnerability. Contribution of Working Group II to the Fourth Assessment Report of the Intergovernmental Panel on Climate Change, Cambridge University Press.

Jacob, D. (2001): A note to the simulation of the annual and inter-annual variability of the water budget over the Baltic Sea drainage basin. - Meteorology and Atmospheric Physics 77: 61-73. CrossRef

Kaspar, F., Schulzweida, U., Müller, R. (2010): Climate data operators as a user-friendly processing tool for CMSAF's satellite-derived climate monitoring products. - Proceedings of the 2010 EUMETSAT Conference. 20. 24. September 2010, Cordoba, Spain.

Kawohl, T. (2013): Regionalization of temperature fields in high mountain and tropical environments - a comparative evaluation. MSc. thesis, University of Hamburg.

Lawrimore, J.H., Menne, M. J., Gleason, B.E., Williams, C. N., Wuertz, D. B. Vose, R. S., Rennie, J. (2011): An overview of the Global Historical limatology Network monthly mean temperature data set, version 3. Journal of Geophysical Research 116 : D19121. CrossRef

Mbaiwa, J. E. (2003): The socio-economic and environmental impacts of tourism development on the Okavango Delta, north-western Botswana. - Journal of Arid Environments 54: 447-467. CrossRef

Mbaiwa, J. E. (2011 ): Changes on traditional livelihood activities and lifestyles caused by tourism development in the Okavango Delta, Botswana. - Tourism Management 32 1050-1060. CrossRef

Meinshausen, M., Smith, S., Calvin, K., Daniel, J.S., Kainuma, M.L.T., Lamarque, J-F, Matsumoto, K., Montzka, S.A., Raper, S.C.B., Riahi, K., Thomson, A., Velders, G.J.M., Vuuren, D.P.P
(2011): The RCP greenhouse gas concentrations and their extension from 1765 to 2500. - Climatic Change 109: 213-241. CrossRef

Mendelsohn, J., Jarvis, A., Roberts, C., Robertson, T. (2002): Atlas of Namibia a portrait of the land and its people. Spearhead Press. Cape Town, South Africa.

Mendelsohn, J., Obeid, S. (2004): Okavango River: The Flow of a Lifeline. Struik Publishers. Cape Town, South Africa.

Mohanakumar, K. (2008): Stratosphere Troposphere Interactions: An Introduction. Springer Netherlands. CrossRef

Reuter, H.I., Nelson, A., Jarvis, A. (2007): An evaluation of void-filling interpolation methods for SRTM data. - International Journal of Geographical Information Science 21: 983-1008. CrossRef

Root, T.L. (2011): Encyclopedia of climate and weather. Vol. 1 . Cambridge.

Skaugen, T. E., Hanssen-Bauer, I., Førland, E.J. (2002): Adjustment of dynamically downscaled temperature and precipitation data in Norway. KLIMA 20/02 Report of The Norwegian Meteorological Institute, Oslo, Norway.

Spekat, A., Kreienkamp, F., Enke, W. (2008): Klimaregionalisierung mit statistischen Methoden. Conference presentation, Annaberger Klimatage, 14 -15.5 .2008 .

Tucker, C. (2004): Writing Geoprocessing Scripts with ArcGIS. Redlands.

Von Storch, H., Zorita, E., Cubasch, U. (1993): An overview of the Global Historical Climatology Network temperature database. - Journal of Climate 6: 1161-1171. CrossRef

Weinzierl, T., Schilling, J. (2013): On demand, development and dependence: a review of current and future implications of socioeconomic changes for Integrated Water Resource Management in the Okavango Catchment of Southern Africa. - Land 2: 60-80. CrossRef

Wetterhall, F., Halldin, S., Xu, C. (2005): Statistical precipitation downscaling with the analogue method. Journal of Hydrology 305: 174-190. CrossRef

\section{Affiliations}

Thomas Weinzierl* (thomas.weinzierl (a) uni-hamburg.de), Olaf Conrad (conrad@geowiss.uni-hamburg.de), Jürgen Böhner (boehner@geowiss.unihamburg.), Jan Wehberg (wehberg@ geowiss.uni-hamburg.) Department of Geography, University of Hamburg Bundesstr. 55

20146 Hamburg, GERMANY 
ECHAM/REMO: Chitembo

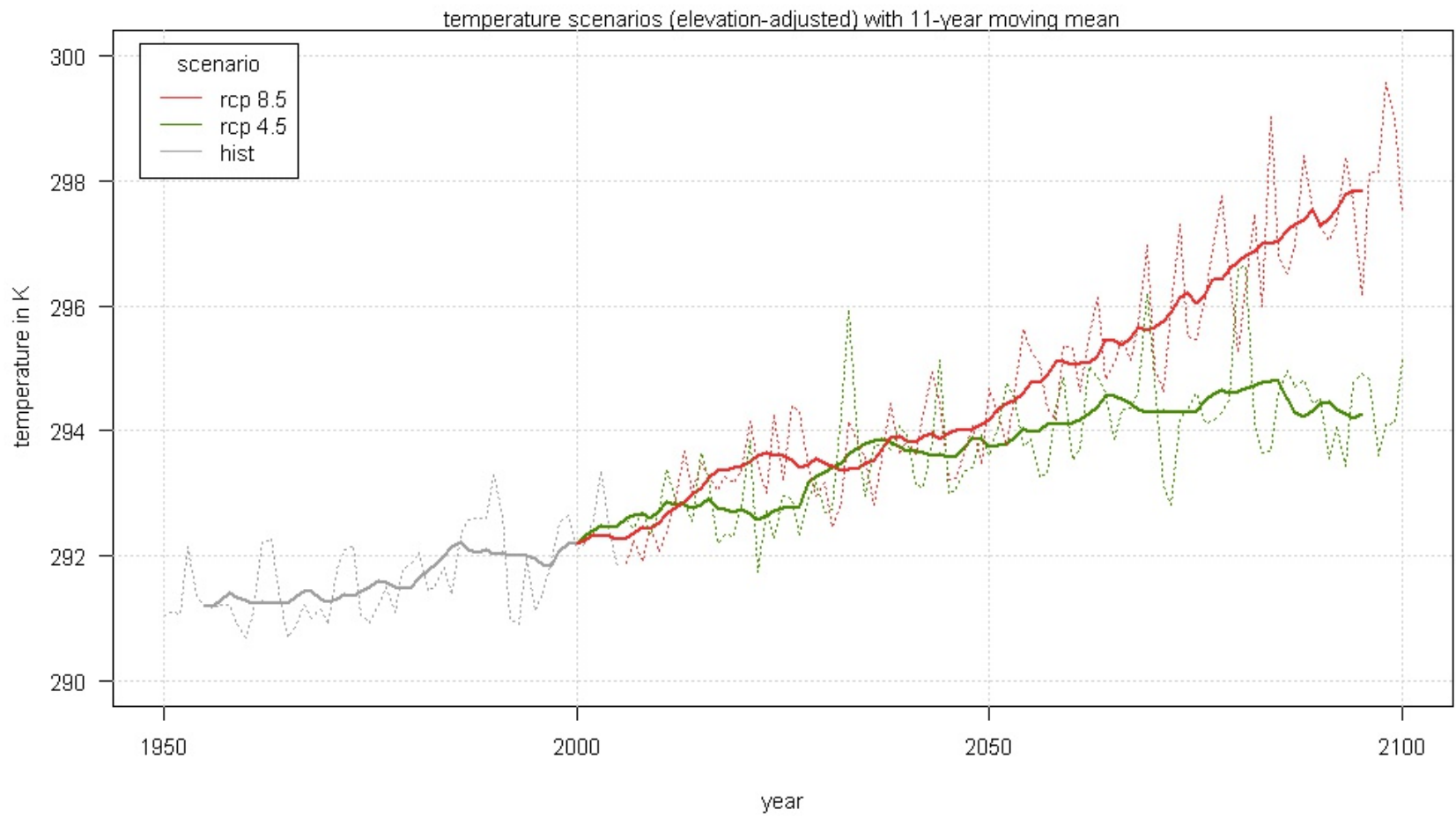

Fig. 7: Time series of regionalized ECHAM/REMO temperature scenarios for Chitembo (Angola).

ECHAM/REMO: Chitembo

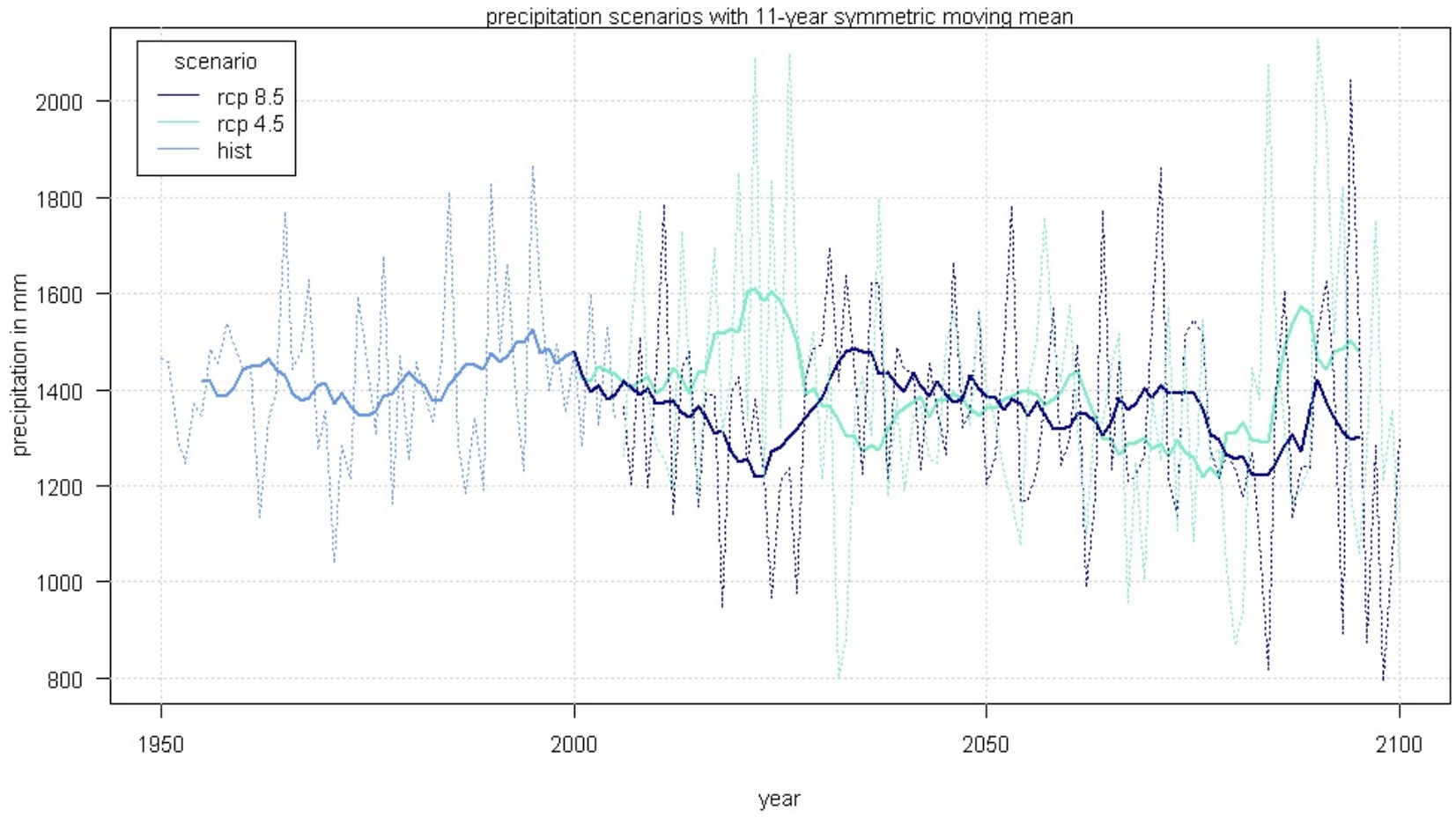

Fig. 8: Time series of regionalized ECHAM/REMO precipitaton scenarios for Chitembo (Angola). 
ECHAM/REMO: Caiundo

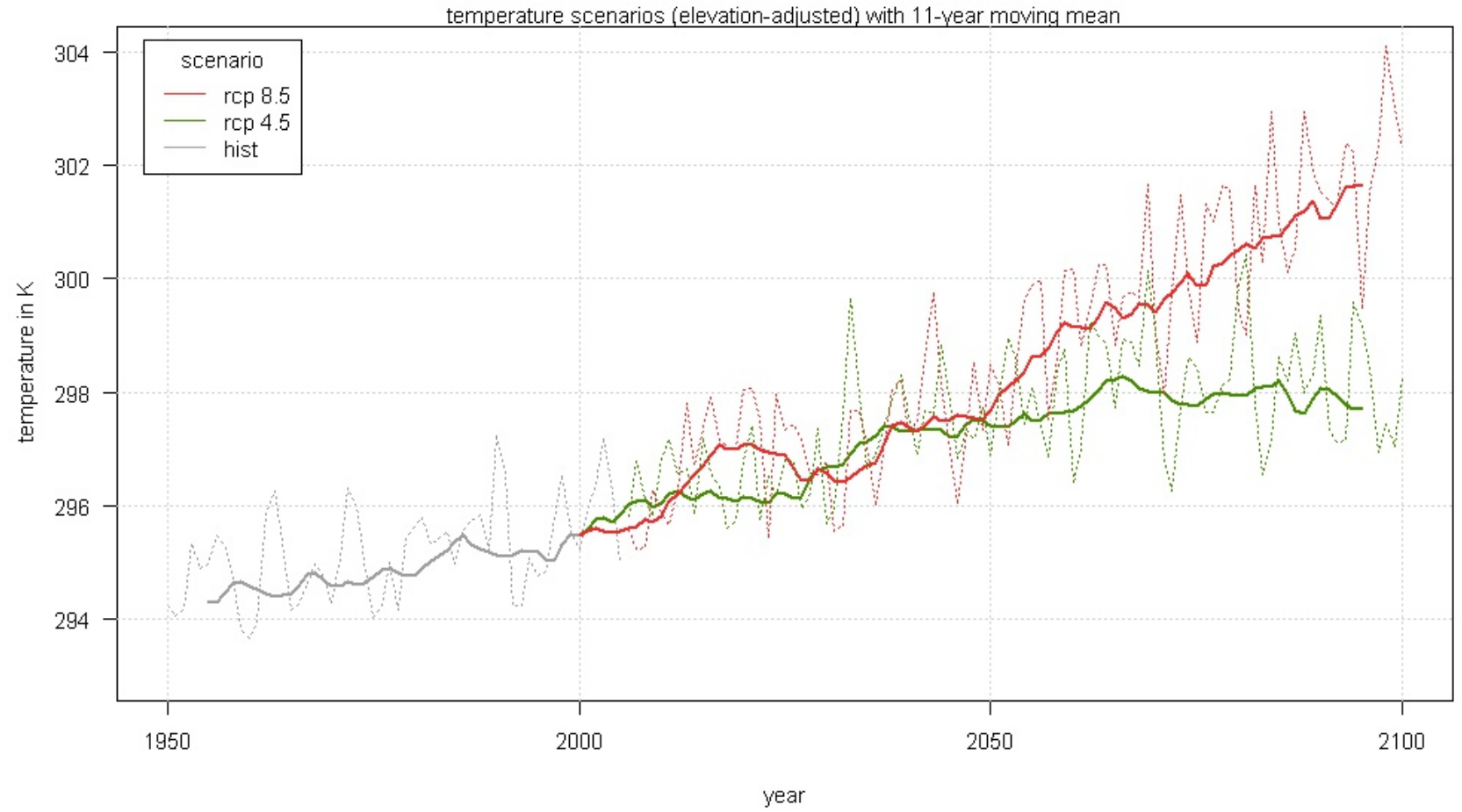

Fig. 9: Time series of regionalized ECHAM/REMO temperature scenarios for Caiundo (Angola).

ECHAM/REMO: Caiundo

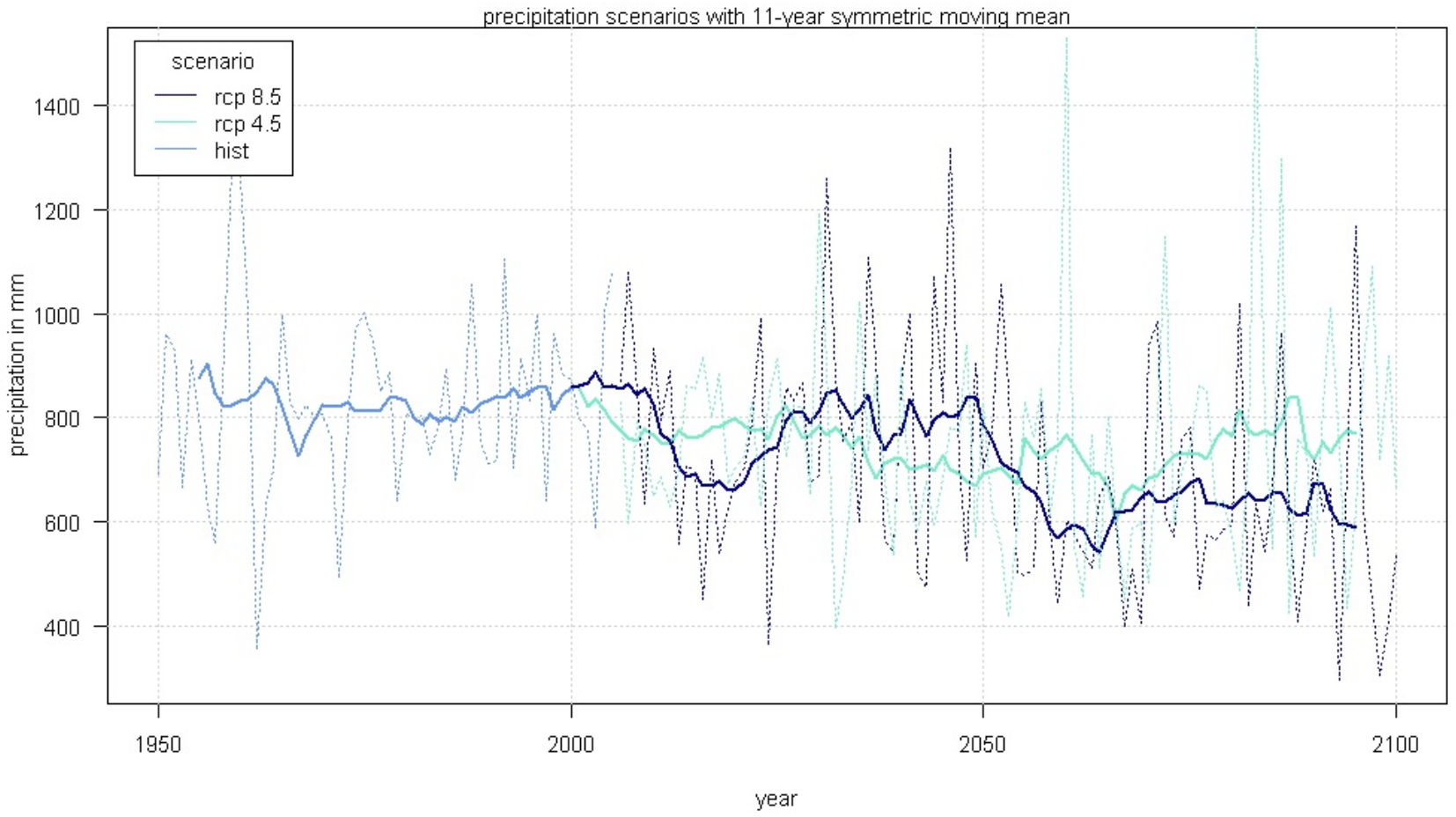

Fig. 10: Time series of regionalized ECHAM/REMO precipitaton scenarios for Caiundo (Angola). 


\section{ECHAM/REMO: Mashare}

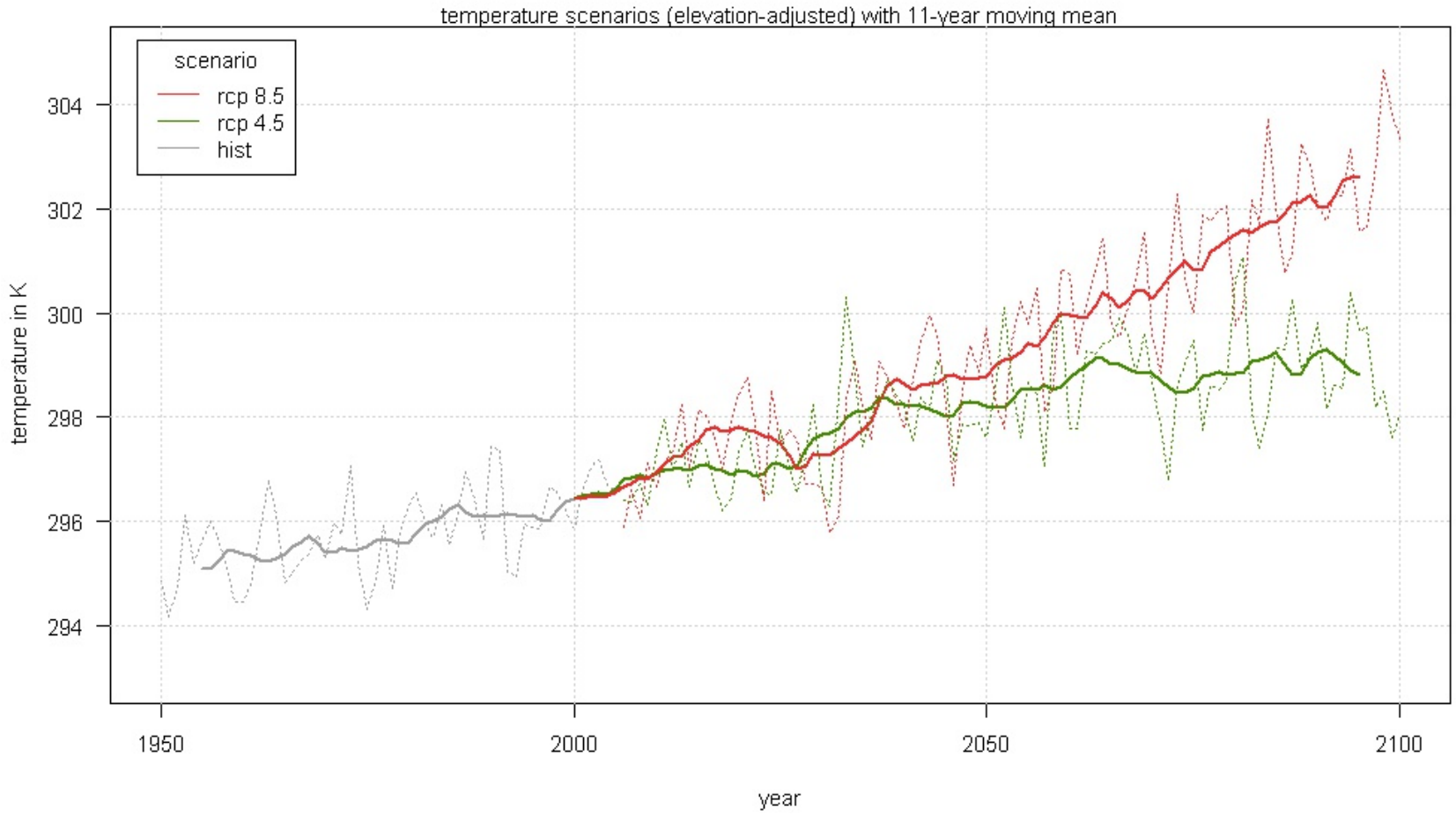

Fig. 11: Time series of regionalized ECHAM/REMO temperature scenarios for Mashare (Namibia).

ECHAM/REMO: Mashare

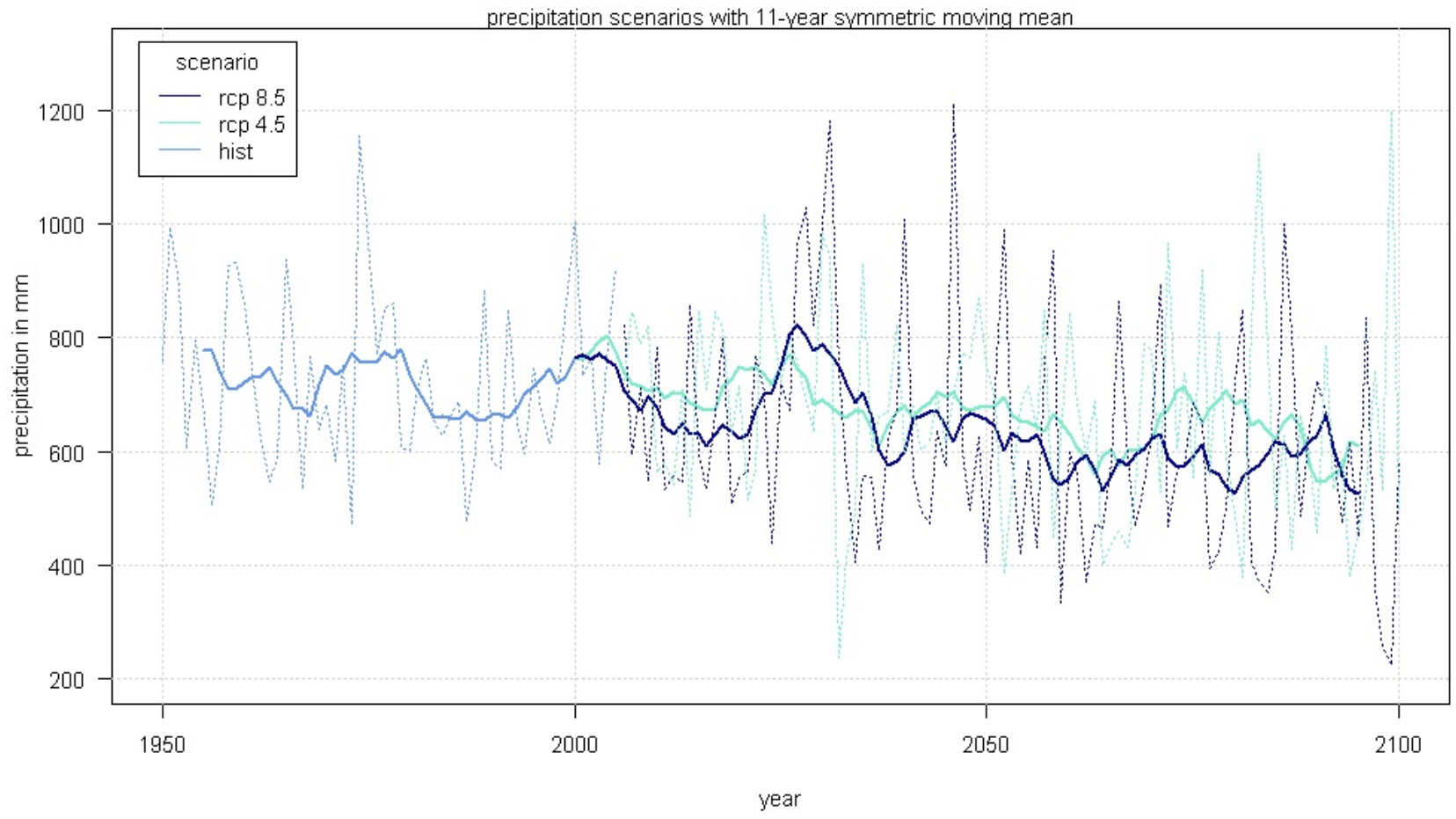

Fig. 12: Time series of regionalized ECHAM/REMO precipitaton scenarios for Mashare (Namibia). 
ECHAM/REMO: Seronga

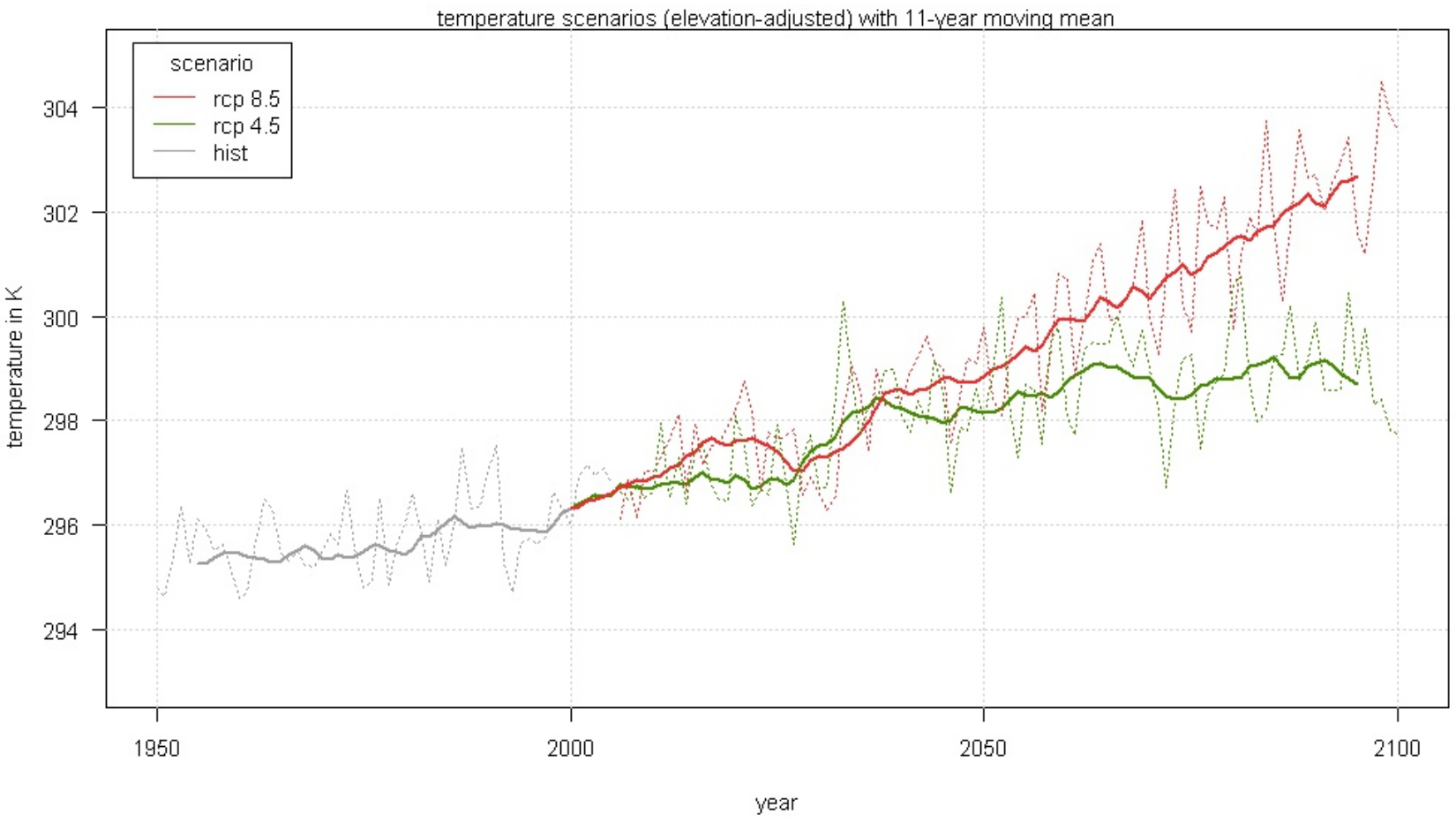

Fig. 13: Time series of regionalized ECHAM/REMO temperature scenarios for Seronga (Botswana).

ECHAM/REMO: Seronga

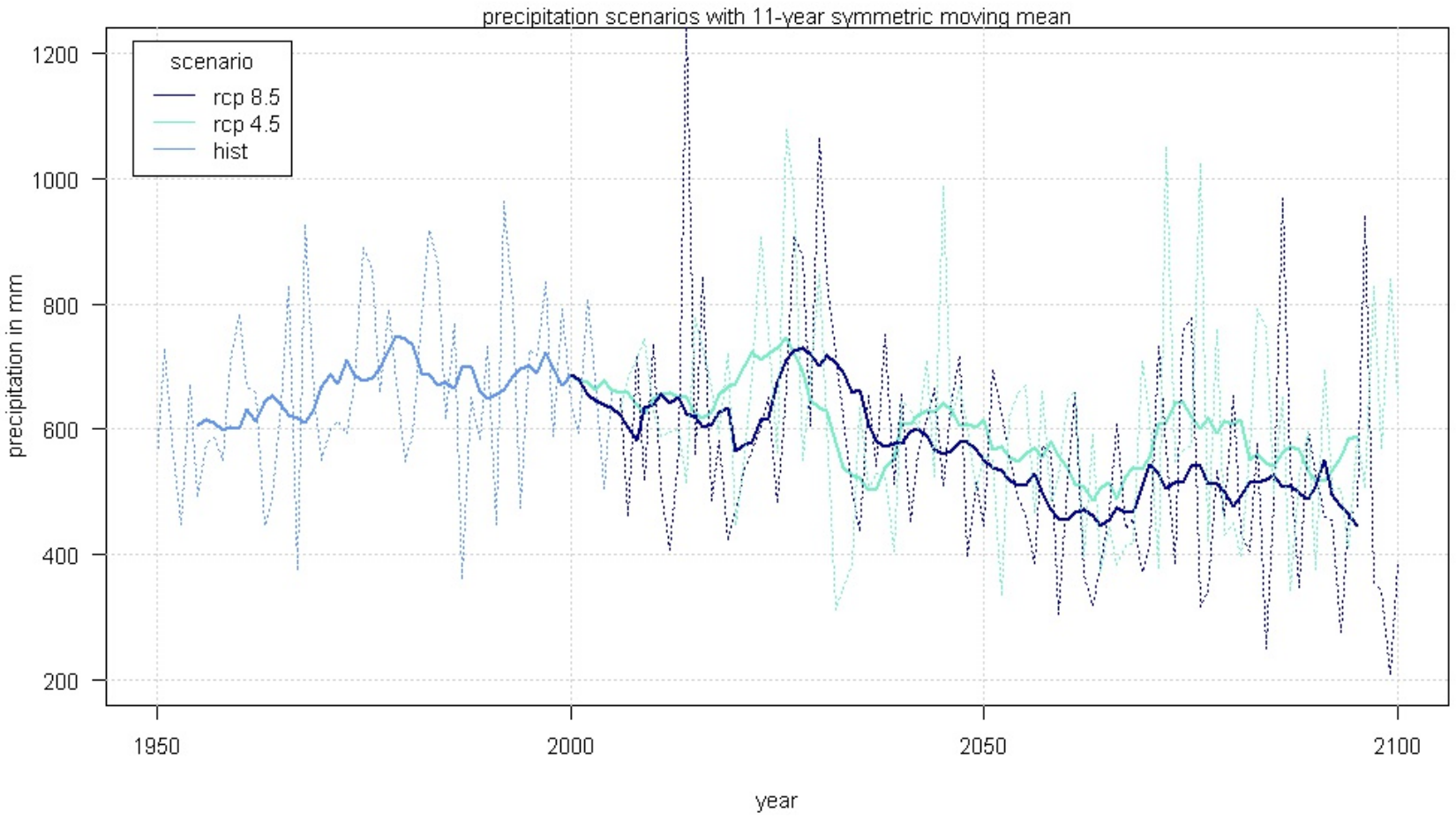

Fig. 14: Time series of regionalized ECHAM/REMO precipitaton scenarios for Seronga (Botswana). 
